Document downloaded from:

http://hdl.handle.net/10251/82245

This paper must be cited as:

Benajes Calvo, JV.; García Martínez, A.; Pastor Enguídanos, JM.; Monsalve Serrano, J. (2016). Effects of piston bowl geometry on Reactivity Controlled Compression Ignition heat transfer and combustion losses at different engine loads. Energy. 98:64-77. doi:10.1016/j.energy.2016.01.014.

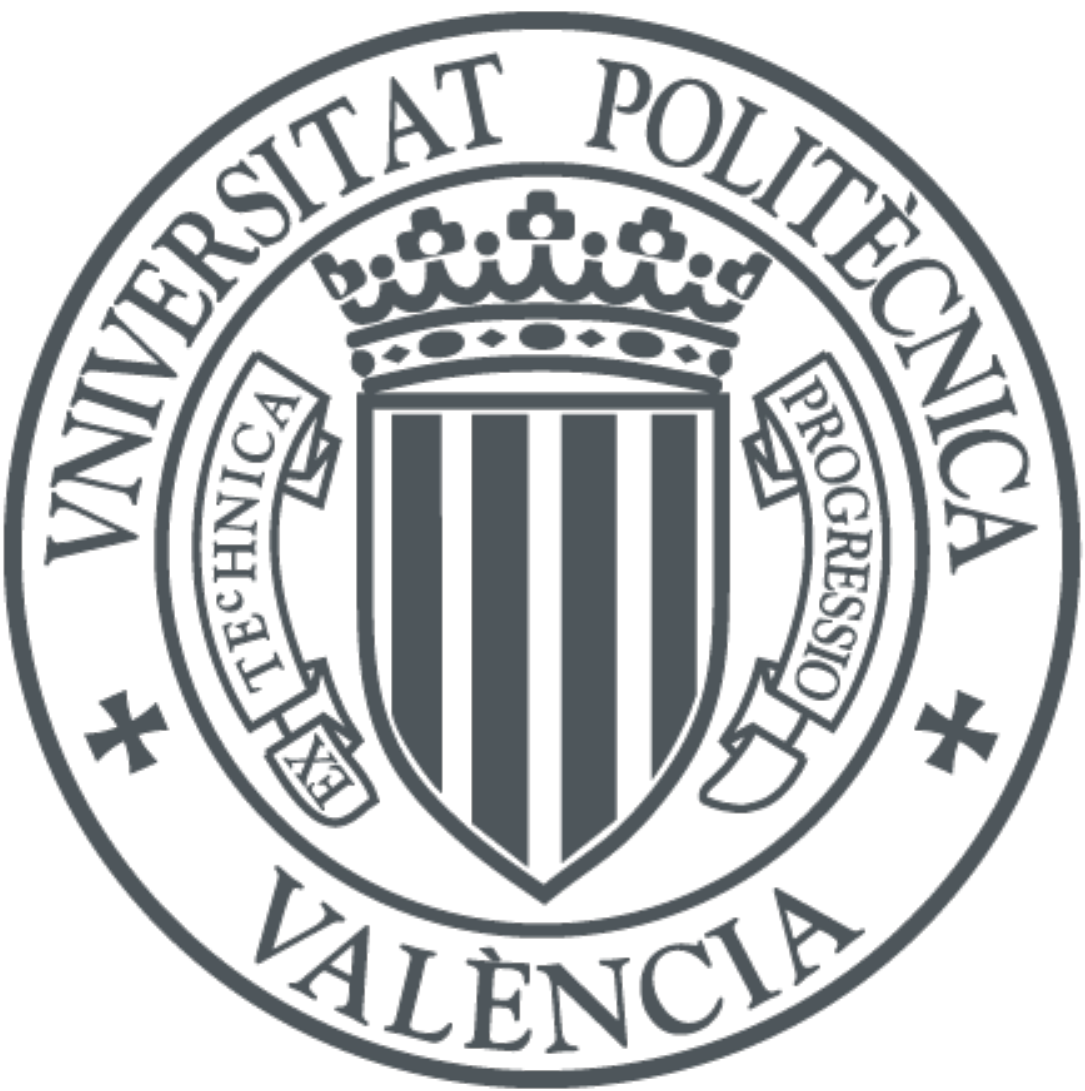

The final publication is available at

http://doi.org/10.1016/j.energy.2016.01.014

Copyright Elsevier

Additional Information 


\title{
Effects of piston bowl geometry on RCCI heat transfer and combustion losses at different engine loads
}

Jesús Benajes, Antonio García*, José Manuel Pastor, Javier Monsalve-Serrano

Energy, Volume 98, 1 March 2016, Pages 64-77. doi:10.1016/j.energy.2016.01.014

CMT - Motores Térmicos, Universitat Politècnica de València, Camino de Vera s/n, 46022 Valencia, Spain

(*) Corresponding author: angarma8@mot.upv.es (Antonio García Martínez)

\begin{abstract}
This work investigates the effects of the piston bowl geometry on RCCl heat transfer and combustion losses and its repercussion on the engine efficiency. For this purpose, three piston geometries with compression ratio 14.4:1 have been studied and compared by means of computational modeling. In addition, the engine operating conditions proposed at low, medium and high load were also validated experimentally in a heavy-duty single-cylinder engine adapted for dual fuel operation. The engine speed was kept constant at $1200 \mathrm{rev} / \mathrm{min}$ during the research.

Results suggest that heat flux through the piston surface represent the major portion of the heat transfer energy. Thus, the comparison of the three geometries demonstrates that reduced piston surface area and reduced charge motion, are the key factors to improve the gross indicated efficiency over the different engine loads. Moreover, it is found that a shallow piston geometry with a smooth transition from the center to the squish region, with a $16 \%$ reduced surface area, strongly improves the gross work at low load. However, this gain diminishes due to increased combustion losses as engine load increases. Finally, an intermediate geometry was confirmed as the best balanced piston geometry for $\mathrm{RCCl}$ operation over the three different loads.
\end{abstract}

\section{Keywords}

Reactivity Controlled Compression Ignition; Heat transfer; Efficiency; Dual fuel; Combustion

\section{Introduction}

The stringent regulations introduced around the world to limit the pollutant emissions in internal combustion engines (ICE) present a major challenge for the engine research community. In spite of its efficiency, conventional mixing-controlled diesel combustion in $\mathrm{Cl}$ diesel engines requires complex and costly exhaust aftertreatment systems to reach the NOx and soot limitation values proposed in the current regulations, such as EURO VI. Specifically, the rich local equivalences ratios and the high temperatures achieved during the conventional diesel combustion (CDC) as well as the oxygen availability in the outside of the spray plume results in an unacceptable emissions. Additionally to the complexity of the aftertreatment systems, the use of DPF (to reduce soot emissions) and LNT or SCR (to minimize NOx emissions) requires a periodically regeneration (operating rich) or the introduction of a reducing agent, which penalizes the fuel consumption. Thus, in order to reduce after- 
treatment costs and fuel consumption it is necessary to avoid the generation of these pollutants in the focus of the emission, i.e. during the combustion development.

Many new compression ignition combustion strategies have been proposed to simultaneously improve the engine efficiency while reducing the NOx and soot emission levels under the regulation limits [1][2]. The more promising combustion strategies are the well-known low temperature combustion (LTC) strategies. A widely investigated combustion strategy is homogeneous charge compression ignition $(\mathrm{HCCl})$, which produces virtually no soot or NOx emissions while maintaining high efficiency [3][4][5]. However, this combustion process presents new challenges with regard to combustion control and engine stress. Due to the rapid heat release, steep pressure gradients occur so that the process has been limited to use within the partial load range [6]. On this regard, Bessonette et al. [7] suggested that different incylinder reactivity is required for the proper $\mathrm{HCCl}$ operation under different operating conditions. Specifically, high cetane fuels are required at low load and a low cetane fuel are needed at medium-high load.

With the aim of improving the $\mathrm{HCCl}$ shortcomings in terms of controllability and knocking, the use of fuels with lower reactivity than diesel fuel (gasoline-like fuels) under Partially Premixed Combustion (PPC) strategies has been widely investigated [8][9][10]. The investigations confirmed gasoline PPC as a promising method to control the heat release rate providing a reduction in NOx and soot emissions [11][12]. Thus, by injecting the fuel later in the engine cycle than in $\mathrm{HCCl}$ strategy, the air-fuel mixing degree is reduced and therefore higher control on the ignition delay as well as the combustion duration is achieved. Additionally, the use of gasoline fuel provides more flexibility to achieve the required extra mixing time at mediumhigh loads [13]. However, the concept has demonstrated difficulties at low load conditions [14][15] using gasoline with octane number (ON) greater than 90 . With the aim of improving the PPC cycle-to-cycle control at low loads using high ON gasolines, PPC spark assisted concept has been studied [16][17]. It has been demonstrated that the spark assistance provides temporal and spatial control over the combustion process [18], however the high local reactivity required between the spark plug electrodes at the start of spark timing and the flame propagation process result in an unacceptable NOx and soot emissions [19]. In this sense, the double injection strategy applied to the PPC spark assisted concept has been confirmed as a suitable strategy to improve the unburned $\mathrm{HC}$ and $\mathrm{CO}$ emissions, but still do not solve the unacceptable NOx and soot emission levels [20][21].

Recent experimental and simulated studies demonstrates that Reactivity Controlled Compression Ignition (RCCl) combustion is a more promising LTC technique than $\mathrm{HCCl}$ and PPC [22][23][24]. RCCI concept is a partially premixed combustion strategy based on dual-fuel operation, which allows using several types of high and low reactivity fuel combinations [25][26]. To delivery both fuels separate injection systems for the low reactivity and high reactivity fuel are used, being port fuel injected (PFI) and direct injected (DI) respectively. Thus, a flexible operation over a wide operating range is possible by modifying both, the low reactivity fuel percentage in the blend and the direct injection timing. The variation of these engine settings provides the required in-cylinder equivalence ratio and reactivity (i.e. octane number) stratification. According to previous studies [27], in which RCCl concept was evaluated from $25 \%$ to full load using the stock piston bowl geometry (CR=14.4:1), RCCI provides very low NOx and soot compared to conventional Diesel combustion (CDC) reference cases. In addition, a benefit in fuel consumption from low to medium load compared to CDC was also appreciated. However, this advantage was not confirmed for higher loads. In spite of the benefits of RCCl concept in terms of fuel consumption, a worse combustion efficiency than CDC was observed, with values around $97 \%$ at low load conditions. In this sense, an experimental investigation combined with computational modelling [28], demonstrated that it is possible to improve the low load combustion efficiency to values above $98 \%$ by combining 
the effects of in-cylinder gas temperature and oxygen concentration respectively with the incylinder fuel blending ratio. Moreover, it was also confirmed that a certain level of unburned $\mathrm{HC}$ and $\mathrm{CO}$ remained unaffected by the engine settings. Finally, recent investigations analyzed their dependency on geometric parameters such as crevices and squish volumes, which difficult the combustion progression resulting in incomplete combustion [29]. In addition, it was identified that $\mathrm{RCCl}$ concept also offers an interesting potential for improving fuel consumption by lowering wall heat transfer. Thus, the main objective of the present work is to evaluate the influence of the piston bowl geometry on $\mathrm{RCCl}$ heat transfer and combustion losses at low, medium and high engine loads and its effects on engine efficiency. For this purpose, additionally to the stock geometry, two piston bowl geometries has been defined and evaluated by means of CFD calculations to obtain further insight in $\mathrm{RCCl}$ heat transfer and unburned products ( $\mathrm{CO}$ and $\mathrm{HC}$ ) formation and destruction during combustion. Moreover, the three piston bowl geometries studied were machined to validate the theoretical findings in a heavy-duty research diesel engine at the three engine loads.

\section{Experimental facilities and processing tools}

\subsection{Test cell and engine description}

A single cylinder, HD diesel engine representative of commercial truck engine, has been used for all experiments in this study. The major difference to the standard unit production is the hydraulic VVA system, which conferred great flexibility during the research. In particular, the valve timing, duration and lift can be electronically controlled for each valve during the engine tests. Thus, an adapted cylinder head to include a dedicated oil circuit is required. Detailed specifications of the engine are given in Table 1.

\begin{tabular}{|l|c|}
\hline Engine type & Single cylinder, 4 St cycle, DI \\
\hline Bore $x$ Stroke [mm] & $123 \times 152$ \\
\hline Connecting rod length [mm] & 225 \\
\hline Displacement [L] & 1.806 \\
\hline Geometric compression ratio [-] & $14.4: 1$ \\
\hline Bowl Type & Open crater \\
\hline Number of Valves & 4 \\
\hline IVO & 375 CAD aTDC \\
\hline IVC & 535 CAD aTDC \\
\hline EVO & 147 CAD aTDC \\
\hline EVC & 347 CAD aTDC \\
\hline
\end{tabular}

Table 1. Single cylinder engine specifications

The engine was installed in a fully instrumented test cell, with all the auxiliary facilities required for its operation and control, as it is illustrated in Figure 1. 


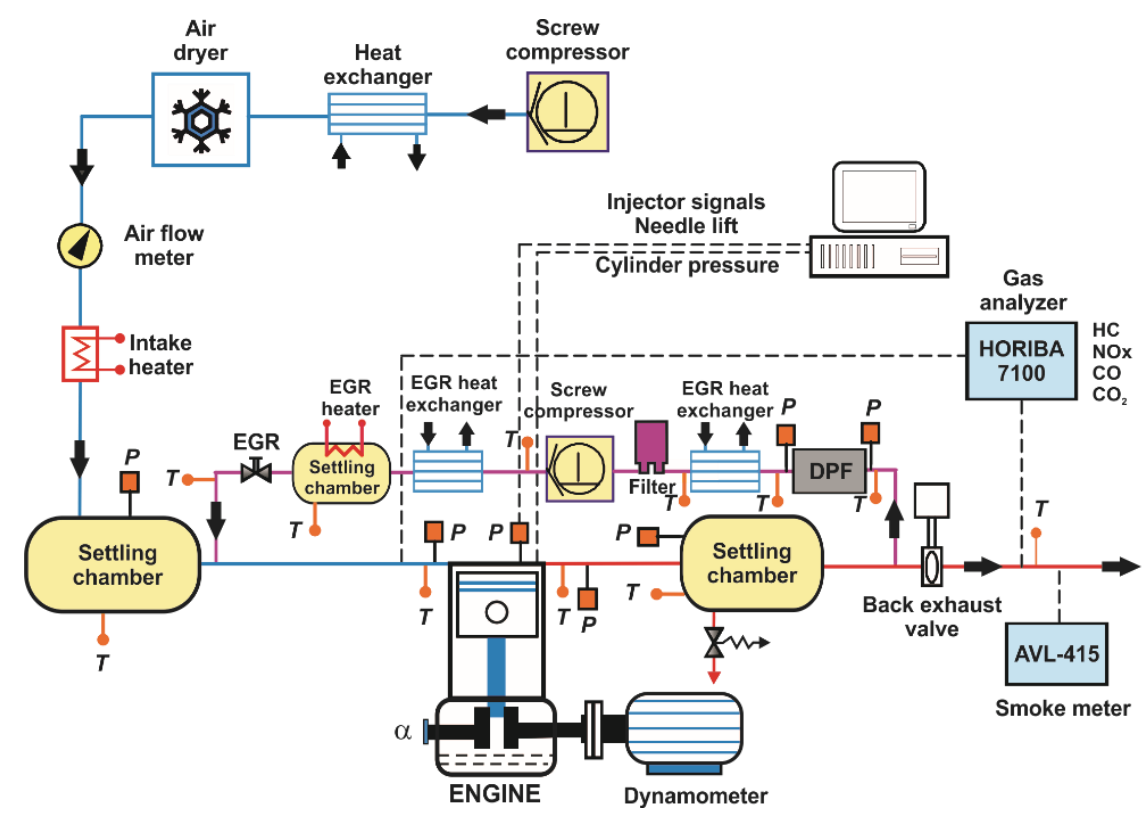

Figure 1. Complete test cell setup

Moreover, to achieve stable intake air conditions, a screw compressor supplied the required boost pressure before passing through an air dryer. The air pressure was adjusted within the intake settling chamber, while the intake temperature was controlled in the intake manifold after mixing with the EGR flow. The exhaust backpressure produced by the turbine in the real engine was replicated by means of a valve placed in the exhaust system, controlling the pressure in the exhaust settling chamber. Low pressure EGR was produced taking exhaust gases from the exhaust settling chamber. The determination of the EGR rate was carried out using the experimental measurement of intake and exhaust $\mathrm{CO}_{2}$ concentration. The concentrations of $\mathrm{NOx}, \mathrm{CO}$, unburned $\mathrm{HC}$, intake and exhaust $\mathrm{CO}_{2}$, and $\mathrm{O}_{2}$ were analyzed with a five gas Horiba MEXA-7100 DEGR analyzer bench by averaging 40 seconds after attaining steady state operation. Smoke emission were measured with an AVL 415S Smoke Meter and averaged between three samples of a 1 liter volume each with paper-saving mode off, providing results directly in FSN (Filter Smoke Number) units. PM measurements of FSN were transformed into specific emissions ( $\mathrm{g} / \mathrm{kWh}$ ) by means of the factory AVL calibration.

\subsection{Piston bowl geometries}

As identified in the introduction section, the potential areas for RCCl optimization are the combustion efficiency and fuel consumption. Thus, in order to reduce the unburned $\mathrm{HC}$ and $\mathrm{CO}$ within the squish region and also to mitigate the wall heat transfer, a series of bowl geometries were designed and evaluated by means of computational calculations and experimental tests.

The first geometry was named as steeped and maintains the stock piston central geometry with a modified transition to the squish region, as shown in Figure 2. The aim of this geometry is to modify the squish flow in order to facilitate the unburned products oxidation and to limit heat transfer in this region [30]. The designed geometry resulted in $4.6 \%$ reduced piston surface versus the stock piston. The second geometry was named as bathtub and was aimed to minimize the squish region with a greater reduction in the piston surface $(16 \%$ reduced versus the stock piston) for lowering heat transfer loss. Further reduction in the piston surface was not possible due to structural constraints of the available piston blanks. It is worthy to note that both designed geometries kept constant the geometric compression ratio of the stock piston, $C R=14.4: 1$. 


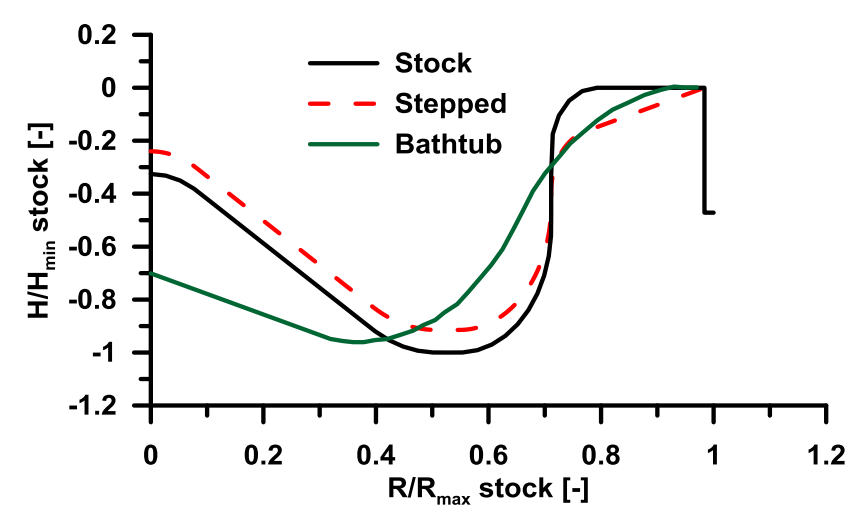

Figure 2. Stock, stepped and bathtub piston geometries

\subsection{Fuels and delivery}

To carry out the experimental tests, commercially available diesel and $98 \mathrm{ON}$ gasoline fuels were selected as high and low reactivity fuels, respectively. Their main properties related with autoignition are listed in Table 2.

\begin{tabular}{|l|c|c|}
\cline { 2 - 3 } \multicolumn{1}{c|}{} & Gasoline & Diesel \\
\hline Density $\left[\mathrm{kg} / \mathrm{m}^{3}\right]\left(\mathrm{T}=15^{\circ} \mathrm{C}\right)$ & 772 & 882 \\
\hline Viscosity $\left[\mathrm{mm}^{2} / \mathrm{s}\right]\left(\mathrm{T}=40^{\circ} \mathrm{C}\right)$ & 0.37 & 2.8 \\
\hline Octane number $[-]$ & 98 & - \\
\hline Cetane number $[-]$ & - & 52 \\
\hline Lower heating value $[\mathrm{kJ} / \mathrm{kg}]$ & 44.542 & 42.651 \\
\hline
\end{tabular}

Table 2. Physical and chemical properties of the fuels used along the study

To enable $\mathrm{RCCl}$ operation the engine was equipped with a double injection system, one for each different fuel used, as it is shown in the scheme of Figure 3. This injection hardware enables to vary the in-cylinder fuel blending ratio and fuel mixture properties according to the engine operating conditions.

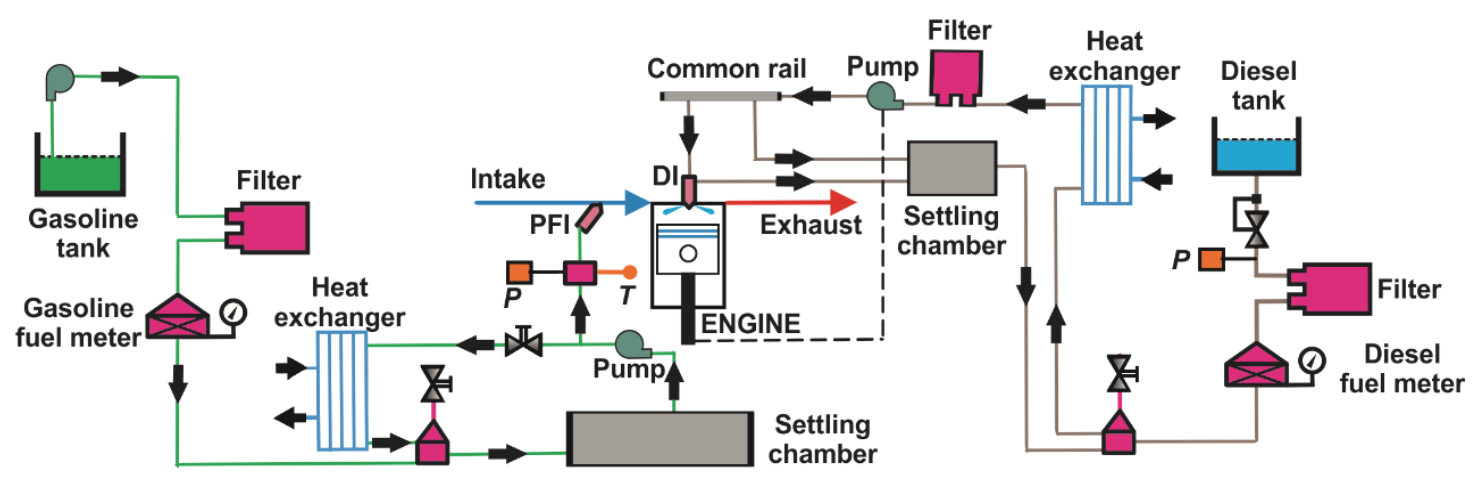

Figure 3. Fuel injection systems scheme

To inject the diesel fuel, the engine was equipped with a common-rail flexible injection hardware which is able to perform up to five injections per cycle; the main characteristic of this hardware is its capability to amplify common-rail fuel pressure for one of the injections by means of a hydraulic piston directly installed inside the injector. The main characteristics of the injector and nozzle used are depicted in Table 3. 


\begin{tabular}{|l|c|}
\hline Actuation Type & Solenoid \\
\hline Steady flow rate @ $100 \mathrm{bar}\left[\mathrm{cm}^{3} / \mathrm{s}\right]$ & 28.56 \\
\hline Number of Holes & 7 \\
\hline Hole diameter $[\mu \mathrm{m}]$ & 194 \\
\hline Included Spray Angle $\left[{ }^{\circ}\right]$ & 142 \\
\hline
\end{tabular}

Table 3. High reactivity fuel injector characteristics

Concerning the gasoline injection, an additional fuel circuit was in-house built with a reservoir, a fuel filter, a fuel meter, an electrically driven pump, a heat exchanger and a commercially available port fuel injector (PFI). The mentioned injector was located at the intake manifold and was specified to be able to place all the gasoline fuel into the cylinder during the intake stroke. Consequently, the gasoline injection timing was fixed 10 CAD after the IVO to allow the fuel to flow along $160 \mathrm{~mm}$ length (distance from PFI location to intake valves seats). Accordingly, this set up would avoid fuel pooling over the intake valve and the undesirable variability introduced by this phenomenon. The main characteristics of the gasoline injector are depicted in Table 4.

\begin{tabular}{|l|c|}
\hline Injector Style & Saturated \\
\hline Steady flow rate @ 3 bar $\left[\mathrm{cm}^{3} / \mathrm{min}\right]$ & 980 \\
\hline Included Spray Angle $\left[^{\circ}\right]$ & 30 \\
\hline Injection Pressure [bar] & 5.5 \\
\hline Injection Strategy & Single \\
\hline Start of Injection Timing & 385 CAD aTDC \\
\hline
\end{tabular}

Table 4. Low reactivity fuel injector characteristics

\subsection{In-cylinder pressure signal analysis}

The combustion analysis was performed with an in-house one-zone model named CALMEC, which is fully described in [31]. This combustion diagnosis tool uses the in-cylinder pressure signal as its main input. The in-cylinder pressure was measured with a Kistler $61215 \mathrm{C}$ pressure transducer coupled with a Kistler 5011B10 charge amplifier. A shaft encoder with 1800 pulses per revolution was used, which supplies a resolution of 0.2 CAD. The pressure traces from 150 consecutive engine cycles were recorded in order to compensate the cycle-to-cycle variation during engine operation. Thus, each individual cycle's pressure data was smoothed using a Fourier series low-pass filter. Once filtered, the collected cycles were ensemble averaged to yield a representative cylinder pressure trace, which was used to perform the analysis. Then, the first law of thermodynamics was applied between IVC and EVO, considering the combustion chamber as an open system because of blow-by and fuel injection. The main result of the model was the Rate of Heat Release (RoHR).

\subsection{Computational model description and validation}

The computational model was built by means of the CONVERGE CFD code [32]. The port fuel injected gasoline is considered to be homogeneously mixed and vaporized at IVC and the diesel injection process is simulated by the standard Droplet Discrete Model [33]. Spray atomization and break-up are modeled using the hybrid KH-RT model [34]. Turbulent flow is modeled by means of the RNG k- $\varepsilon$ model with wall-functions in order to account for wall heat transfer [34]. Concerning combustion modeling, a direct integration of detailed chemistry approach was used by means of the CONVERGE code and the SAGE solver. A multi-zone model from Babajimopoulos et al. [35] is used to solve the detailed chemistry in zones, i.e., groups of cells that have similar thermodynamic state, in order to speed-up chemistry calculations. Cells are grouped based in two variables, temperature and equivalence ratio. The calculations performed in this project use a $5 \mathrm{~K}$ bin size for temperature and 0.01 bin size for equivalence ratio zones. 
A reduced reaction mechanism made up of 45 species and 142 reactions [36] including NOx formation (thermal, $\mathrm{N}_{2} \mathrm{O}$ and $\mathrm{NO}_{2}$ pathways) describes the combined oxidation of $n$-heptane (PRF 0) and iso-octane (PRF 100). The use of these PRF as surrogate fuels is widely accepted to represent the combustion characteristics of diesel and gasoline, respectively [37][38]. On the other hand, the physical properties of diesel fuel are represented by the diesel 2 fuel surrogate available in CONVERGE for spray and mixing process.

Calculations run from Intake Valve Close (IVC) with initial thermodynamic conditions as well as wall temperatures estimated from experimental data by means of the in-house combustion diagnostics code CALMEC. Thus, closed-cycle computations on sector grids with periodic boundaries were carried out due to computational efficiency. In these calculations $1 / \mathrm{n}^{\text {th }}$ of the combustion chamber, being $n$ the number of nozzle orifices, is modeled. The CFD code uses a structured cartesian grid with base cell size of $1.6 \mathrm{~mm}$. Two additional grid refinements were performed by means of an adaptive mesh refinement (AMR) as well as a fixed refinement within the spray region, as shown in Figure 4. In addition to the crevice volume upto the fire ring included in the computational domain, a crevice model [39] was also used in order to account for the flow between the cylinder, piston rings and the crank-case and its effect on unburned $\mathrm{HC}$ emissions.
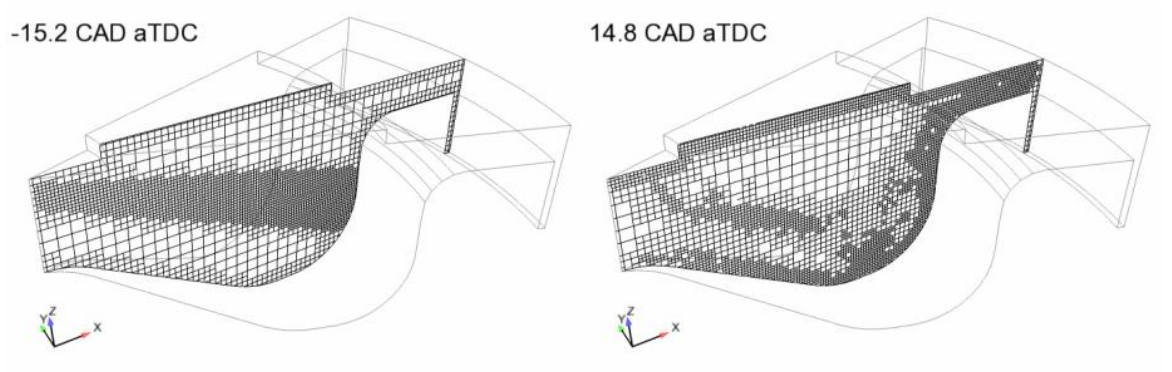

Figure 4. Different grid refinements by CONVERGE adaptive mesh refinement. Left: computational grid at -15.2 CAD aTDC. Right: computational grid at +14.8 CAD aTDC

Figure 5 shows a comparison of the rate of heat release (RoHR) for the experimental and computational results at low load operating conditions for the three piston geometries. In addition, the experimentally measured and model-predicted $\mathrm{HC}$ and $\mathrm{CO}$ emissions are depicted in the figure. The engine operating conditions set to validate the model are representative of the conditions set in the present study. In particular, the diesel injection was set at $-60 /-35$ CAD aTDC with an EGR rate of $45 \%$ and intake temperature of $40^{\circ} \mathrm{C}$. From the figure, it can be seen that the model fairly predicts the combustion characteristics as well as the $\mathrm{HC}$ and $\mathrm{CO}$ emissions trend between the three geometries when comparing with the experimental results. It is interesting to note that $\mathrm{HC}$ emissions are significantly underpredicted, probably due to the slight differences in the maximum RoHR peaks among the modeling and the experiments. Because the simulations are capable of capturing the experimental variations found between the three geometries, they are used to understand the combustion efficiency trends observed in the next sections. 

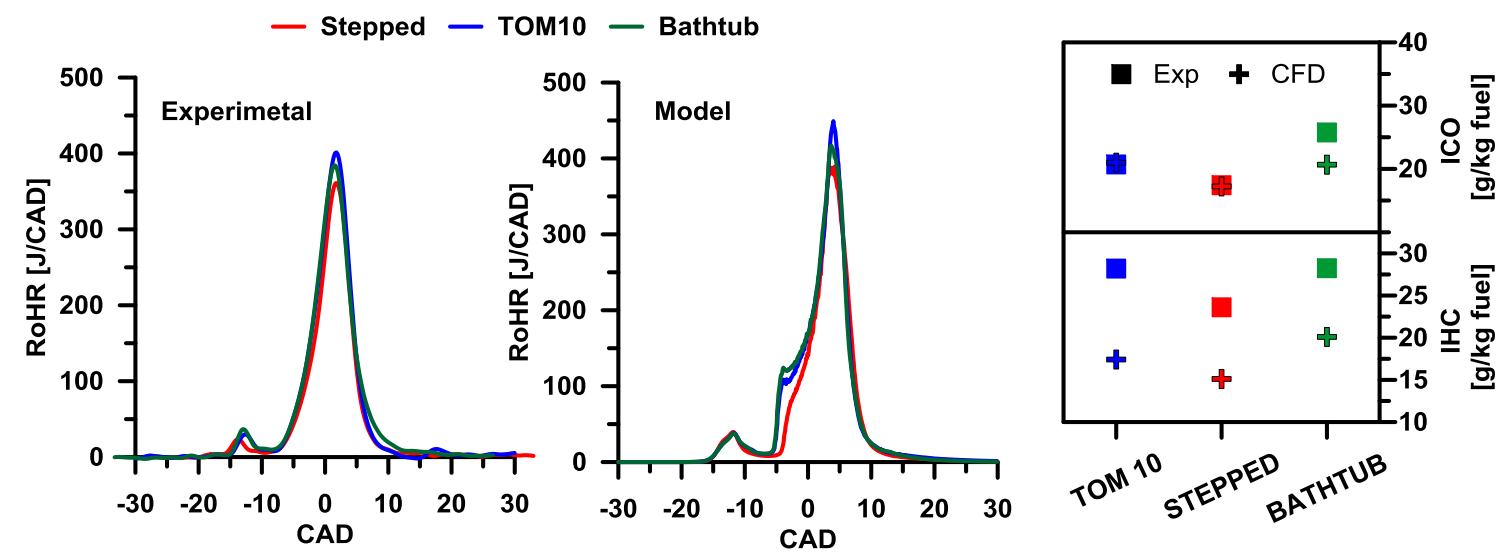

Figure 5. Comparison of the in-cylinder pressure, RoHR, HC and CO for the experimental and computational results at low load conditions with the three piston geometries. Double diesel injection set at -60/-35 CAD aTDC, EGR rate of $45 \%$ and intake temperature of $40^{\circ} \mathrm{C}$.

\section{Low loads results}

Previous studies [24], aimed to provide suitable engine settings for $\mathrm{RCCl}$ concept at 1200 $\mathrm{rev} / \mathrm{min}$, proved experimentally the benefits of the double injection versus the single injection strategy for RCCl low load conditions. Thus, an advanced double injection strategy resulted in a simultaneous reduction in NOx emissions and fuel consumption while maintaining soot emissions under EURO VI limitation. By contrast, the reduction in NOx emissions using a single injection strategy resulted in an increase in fuel consumption. Thus, the present study focused only on the more efficient strategy, the double injection one. The operating conditions are summarized in table 5.

\begin{tabular}{|l|c|}
\hline Diesel injection schedule [-] & Double \\
\hline Diesel injection timing [CAD aTDC] & $-60 /-35$ \\
\hline Gasoline injection timing [CAD aTDC] & -335 \\
\hline Gasoline fraction [\%] & 75 \\
\hline Total injected mass [mg] & 70 \\
\hline Intake temperature [ $\left.{ }^{\circ} \mathrm{C}\right]$ & 40 \\
\hline Engine speed [rev/min] & 1200 \\
\hline Compression Ratio [-] & $14.4: 1$ \\
\hline Intake oxygen mass fraction [\%] & 15.3 \\
\hline
\end{tabular}

Table 5. Operating conditions for the low load study

\subsection{Heat transfer analysis}

Figure 6 show the global instantaneous heat flux (HF) as well as its breakdown among piston, cylinder and cylinder head for the three piston geometries. As can be seen, the stock piston leads to higher global HF than stepped and bathtub piston during the whole combustion cycle. This fact is mainly associated to the greater HF through the piston surface, which represents around $50 \%$ of the global HF. On the other hand, it is also observed a slightly higher HF through the cylinder head from +20 to +40 CAD aTDC in the case of stock piston. Finally, the comparison of stepped and bathtub pistons reveals a minimum differences in the global HF. It seems that the reduced piston HF for bathtub piston during the whole cycle was balanced with 
an increase in the piston and head HF, which denotes differences in the combustion progression and charge motion between both pistons.

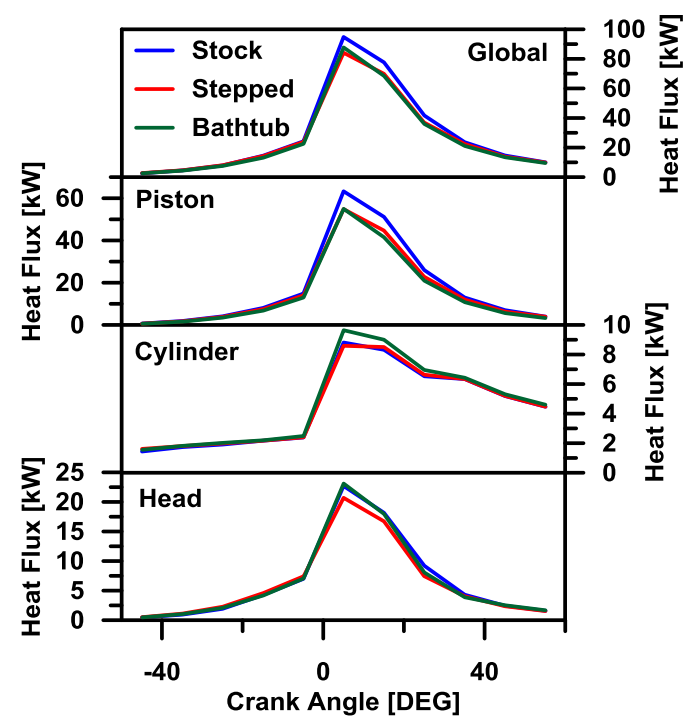

Figure 6. Heat flux breakdown between piston, cylinder and cylinder head for the stock, stepped and bathtub pistons at low load.

In order to assess the spatial differences during the combustion progression, the Figure 7 shows a comparison of the temperature distribution between the three pistons. A cut plane coincident with the spray axis as well as an iso-surface of temperature are represented. In particular, $\mathrm{T}=1500 \mathrm{~K}$ was selected as representative value of the high temperature regions in the chamber. In addition, the value of the HT coefficient together with the instant of the combustion cycle are depicted in each sub-figure. In this sense, it is interesting to remark that the lower squish distance for the stock piston results in higher squish velocities during the compression stroke leading to a higher HT coefficient during the whole combustion cycle.

Looking the first instant (-5 CAD aTDC), it is clear that the ignition pattern is equal for the three pistons. Thus, the first spot of the high temperature combustion appears in the piston surface, where a reactive equivalence ratio is found due to the impact of the main diesel injection with the piston wall. After that, the charge is sequentially consumed from more-to-less reactive regions. From the second instant represented (+5 CAD aTDC), it is seen that the combustion propagates over the piston surface leading to high temperature regions in that zone. Thus, the greater area of the stock piston together with the higher HT coefficient, explain the significantly higher piston HF depicted in Figure 6. Also of note is that the smoother transition from the piston center to the squish region for stepped and bathtub piston enhances the high temperature propagation until that zone. At +15 and +25 CAD aTDC, it is seen that the high temperature regions near the cylinder head are more evident for stepped and bathtub piston than for stock piston. Finally, comparing the late combustion instants (+41 CAD aTDC) it is found that the less steep geometry of bathtub piston enhances the propagation of the high temperature until the cylinder walls, which results in a peak of HF in this zone (Figure 6). 


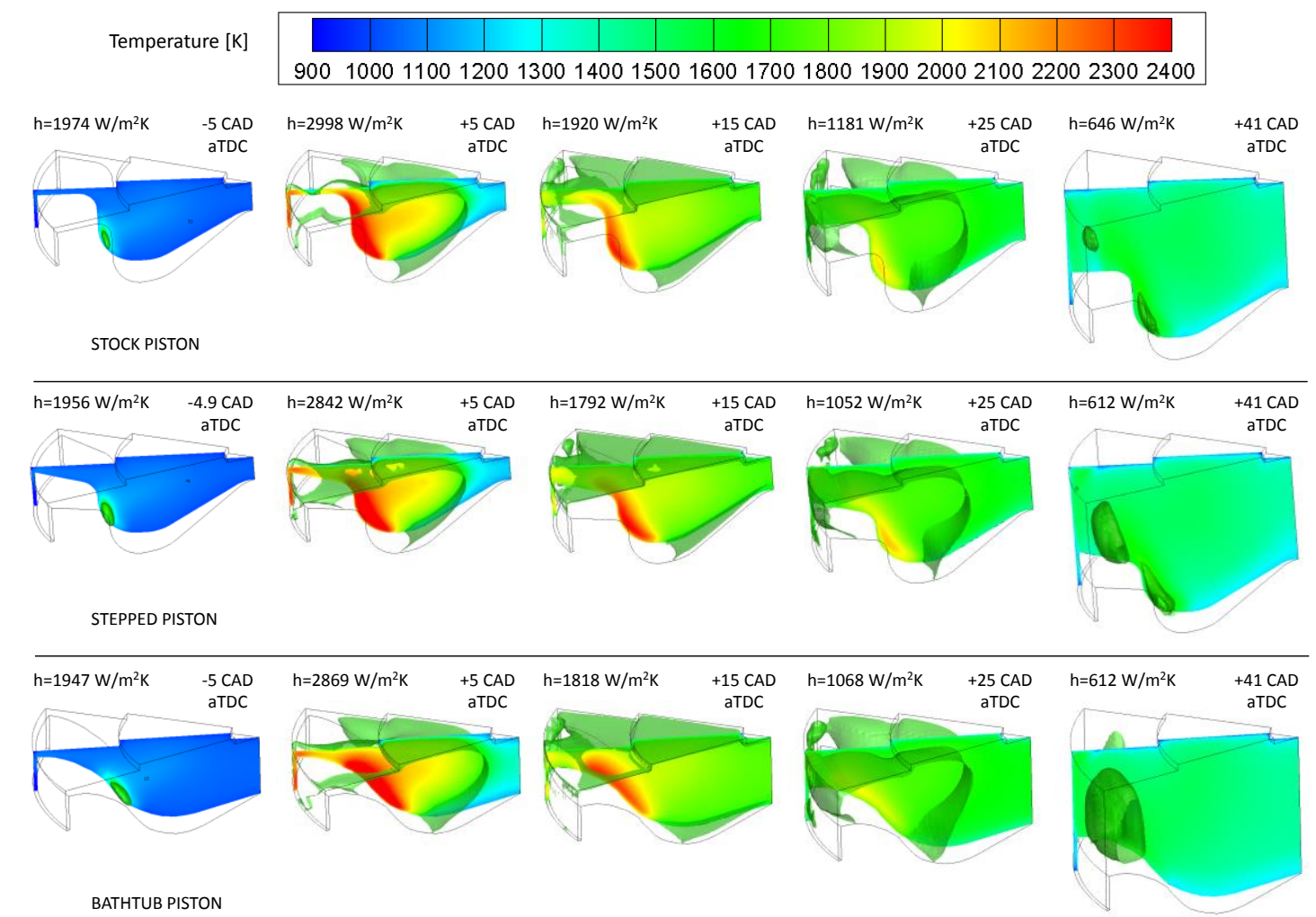

Figure 7. Comparison of the temperature distribution between the stock, stepped and bathtub pistons at low load. A cut plane coincident with the spray axis, an iso-surface of $\mathrm{T}=1500 \mathrm{~K}$ and the heat transfer coefficient are represented in each case.

To sum up, Figure 8 shows the HT breakdown and total HT energy for the three piston geometries. It is interesting to remark that, compared to the stock geometry, bathtub piston allows the greatest reduction in the total HT energy. Taking into account the combustion pattern explained above, this fact it is well related with the reduction in piston area coupled with the notable lower HT coefficient than the stock piston. On the other hand, the modification in the piston geometry changed the ratio between the HT through the cylinder walls and cylinder head. Thus, the new geometries enhanced the propagation of the high temperature until the cylinder walls, which causes a significant HT increase in this zone. In this regard, the greater HT through cylinder and head for bathtub piston balances the total HT energy with the stepped piston.

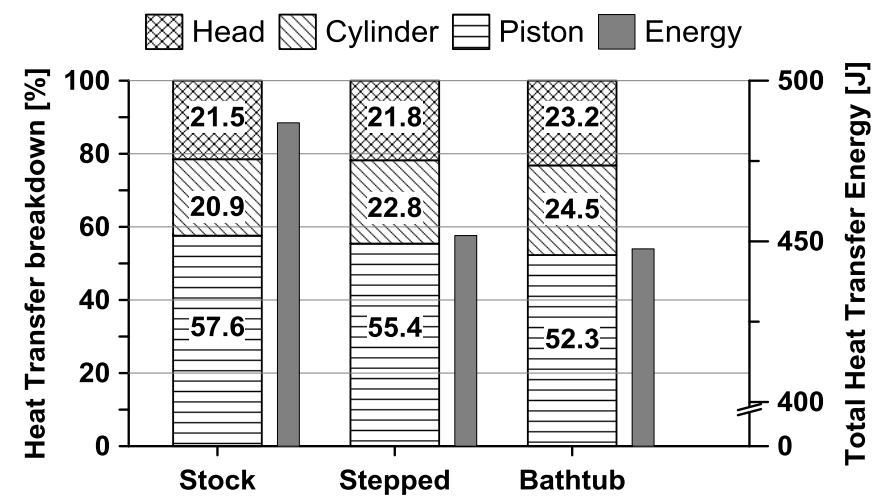

Figure 8. Comparison of the heat transfer breakdown and total heat transfer energy between the stock, stepped and bathtub pistons at low load. 


\subsection{Combustion Losses}

Figure 9 (left) shows the temporal evolution of $\mathrm{HC}$ and $\mathrm{CO}$ emissions predicted by the model as well as their corresponding experimental measurements. As can be seen, the predicted $\mathrm{HC}$ and $\mathrm{CO}$ values at the end of the combustion cycle have the same order of magnitude for the three pistons, which is also observed in the experimental measurements. In spite of that, notable differences in $\mathrm{HC}$ and slight differences in $\mathrm{CO}$ evolution during the combustion cycle are observed comparing the three pistons.
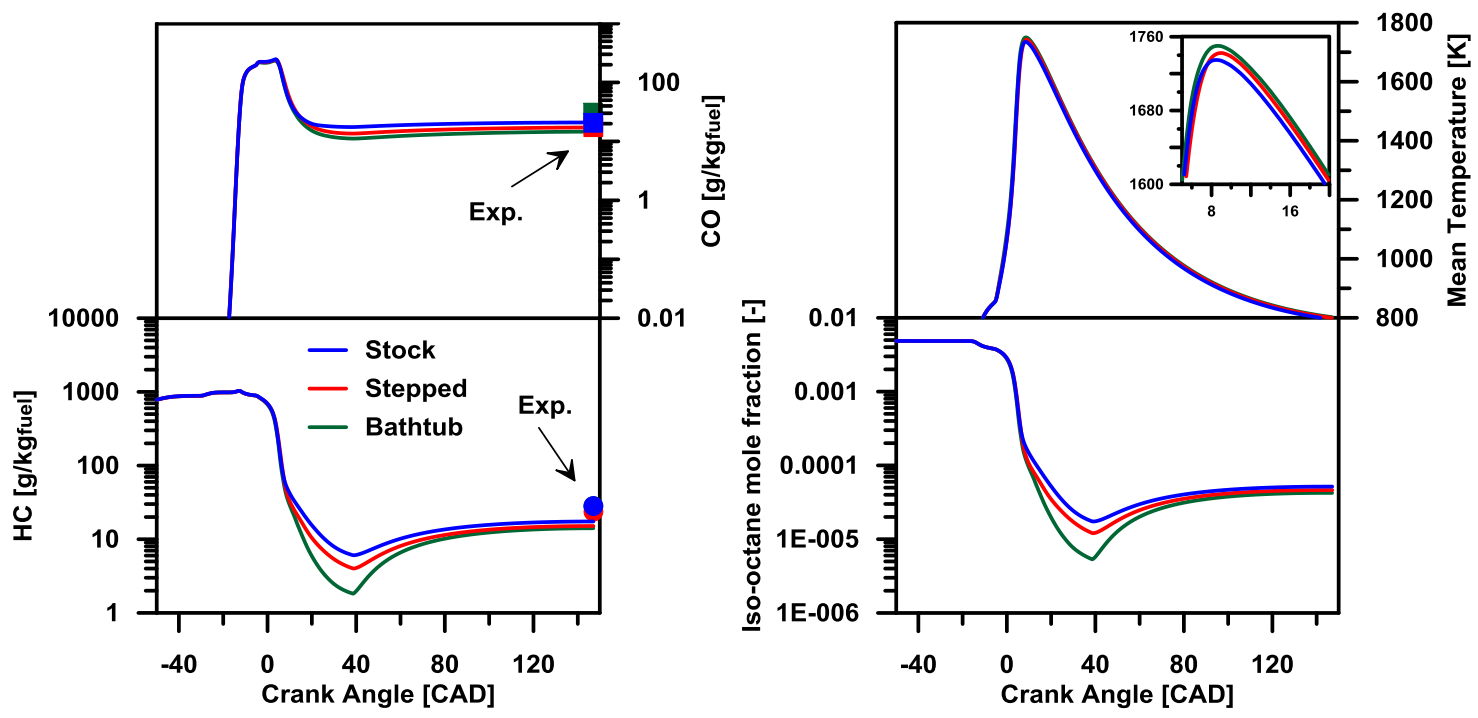

Figure 9. Comparison of the experimental and model predicted $\mathrm{HC}$ and $\mathrm{CO}$ emissions between the stock, stepped and bathtub pistons at low load (left). Instantaneous iso-octane mole fraction and mean temperature predicted by the model (right).

In order to understand the source of the combustion losses as well as the differences in their evolutions when comparing the three pistons, the Figure 9 (right) shows the evolution of the iso-octane mole fraction and the mean temperature predicted by the CFD model. As seen from the figure, the $\mathrm{HC}$ evolution as well as its trend with respect to the different pistons are equal to the ones observed for the iso-octane mole fraction. Moreover the $\mathrm{CO}$ emissions at the end of the cycle are also related with the iso-octane ones and its evolution is directly linked with the mean temperature in the chamber. Thus, it is proved that the main cause of the combustion losses at low load is the poor oxidation of the iso-octane. Finally, the comparison of the iso-octane oxidation between the three pistons reveals some differences, which are related with the spatial differences during the combustion progression. In this sense, the higher mean temperature for bathtub and stepped pistons together with the spatial propagation enhancement of the high temperature in the chamber, resulted in improved isooctane oxidation.

\subsection{Efficiency}

Figure 10 shows a comparison of the fuel energy usage between stock, stepped and bathtub pistons at low load. Thus, a direct comparison of its influence on engine efficiency can be carried out. 


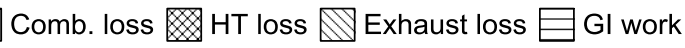

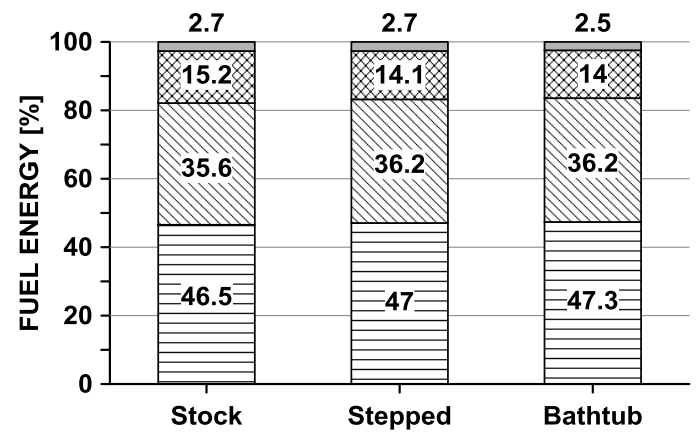

Figure 10. Comparison of the fuel energy usage between the stock, stepped and bathtub pistons at low load.

As can be seen, stepped and bathtub pistons reduce the HT losses significantly compared to the stock piston. However, a portion of this energy is merely rejected as thermal exhaust loss due to the higher exhaust temperature, and a portion of it is extracted as additional gross work. In addition, bathtub piston slightly reduce the combustion losses, which promotes higher gross indicated work than stepped piston at low load.

\section{Medium load}

Previous findings at medium load demonstrated that the use of high gasoline fractions coupled with advanced double diesel injection strategies, resulted in the best settings for RCCI operation [27]. Thus, the operating conditions set in this study are summarized in table 6 . It should be remarked that the effective compression ratio was lowered to $11: 1$ by means of advancing the intake valves closing event (early Miller cycle) in order to ensure a moderated maximum pressure rise rate peaks and preserve the engine mechanical integrity.

\begin{tabular}{|l|c|}
\hline Diesel injection schedule [-] & Double \\
\hline Diesel injection timing [CAD aTDC] & $-60 /-40$ \\
\hline Gasoline injection timing [CAD aTDC] & -335 \\
\hline Gasoline fraction [\%] & 80 \\
\hline Total injected mass [mg] & 119 \\
\hline Intake temperature [ $\left.{ }^{\circ} \mathrm{C}\right]$ & 40 \\
\hline Engine speed [rev/min] & 1200 \\
\hline Compression Ratio [-] & $11: 1$ \\
\hline Intake oxygen mass fraction [\%] & 15 \\
\hline
\end{tabular}

Table 6. Operating conditions for the medium load study

\subsection{Heat transfer analysis}

The global instantaneous heat flux (HF) at Figure 11, shows that the HF for bathtub piston is under the other two pistons over the entire evolution. On the other hand, the stock and stepped pistons leads to similar evolution in terms of global HF, with colliding profiles in most instants of the combustion cycle. Analyzing the apportionment among piston, cylinder and cylinder head for the three piston geometries, more differences are noted. In particular, the same findings than at low load are found regarding the piston HF. Thus, the values are well related with the differences in the piston surface area. On the other hand, stepped piston shows a remarkable HF through the cylinder wall during the late combustion. Finally, it is clear that the stock piston minimizes the HF through the cylinder head. 


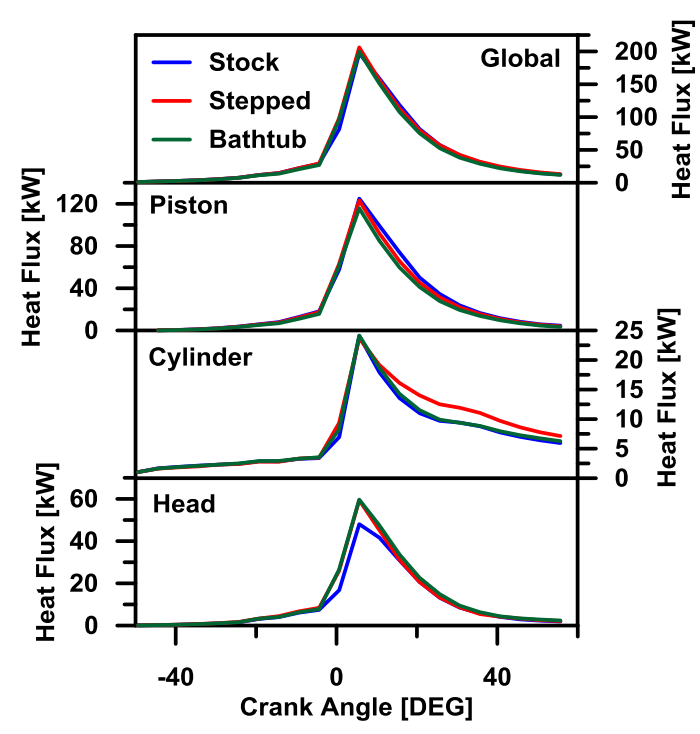

Figure 11. Heat flux breakdown between piston, cylinder and cylinder head for the stock, stepped and bathtub pistons at medium load.

Figure 12 shows the in-cylinder temperature distribution for the three piston geometries. A cut plane coincident with the spray axis, a cut plane near the cylinder wall and an iso-surface of $\mathrm{T}=1500 \mathrm{~K}$ are represented. The first instant represented reveals the same ignition pattern that the one described at low load conditions. This similitude is explained due to the minor differences among the injection strategies proposed. It is worthy to note that the temperature rise near the piston wall is more evident for bathtub piston only because of the instant represented ( 0.5 CAD delayed versus the other pistons). Later, the combustion also propagates near the piston wall through the high reactivity regions created by the main injection. At this instant ( $\approx+5$ CAD aTDC), the major difference found with respect to low load is the greater temperature in the squish region for the stepped piston. It should be related with the advance in the main injection (-40 instead of -35 CAD aTDC), which provokes that greater part of the fuel gets out of the piston bowl. Regarding the next instants of the engine cycle, there are no significant differences in combustion development comparing to low load. 


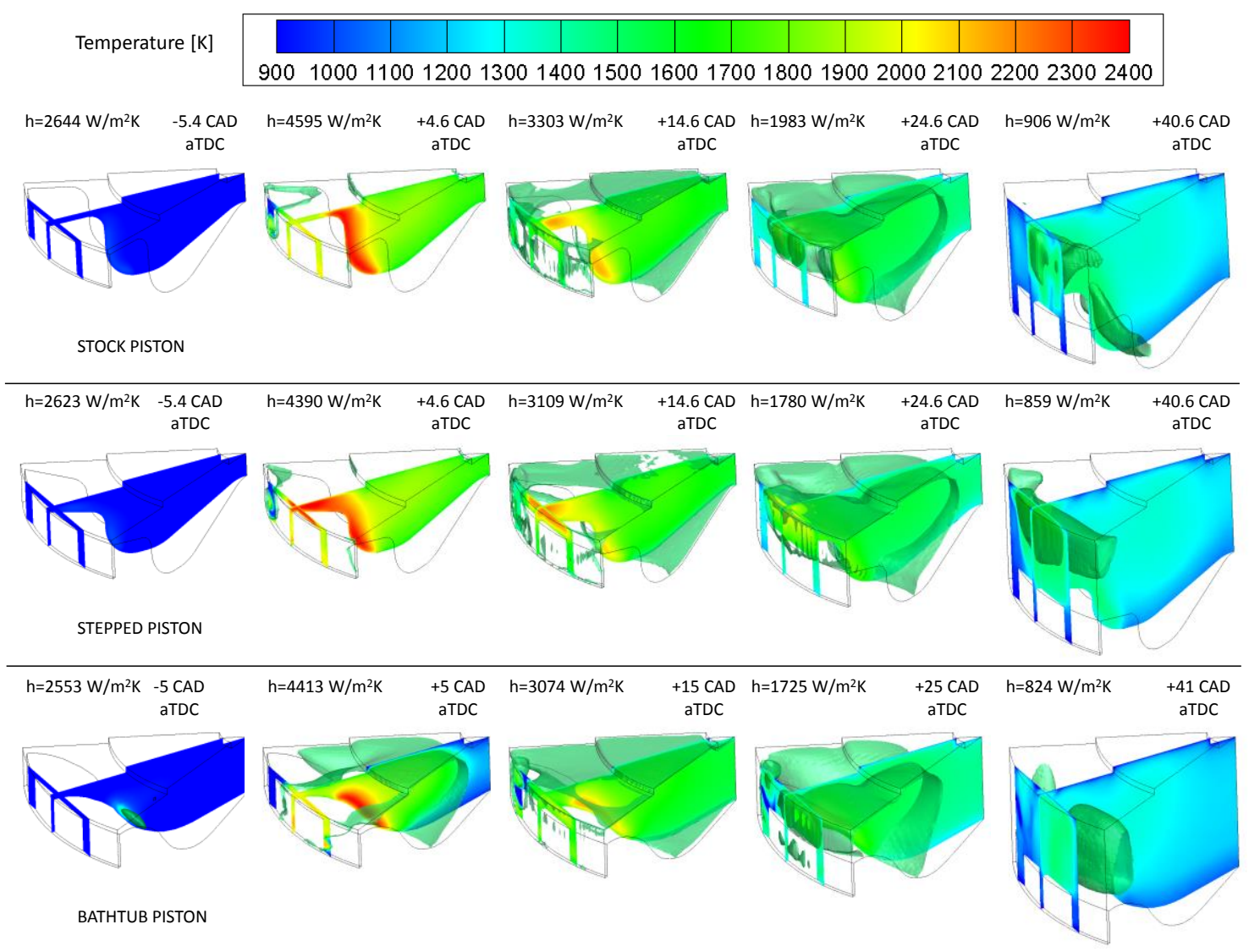

Figure 12. Comparison of the temperature distribution between the stock, stepped and bathtub pistons at medium load. A cut plane coincident with the spray axis, an iso-surface of $\mathrm{T}=1500 \mathrm{~K}$ and the heat transfer coefficient are represented in each case.

Finally, Figure 13 provides evidence that bathtub piston also allows the greatest reduction in the total HT energy at medium load. It should be related with its reduced piston surface area, which strongly minimize the HT through the piston wall. By contrast, looking at Figure $12(+15$ and +25 CAD aTDC) it is stated that bathtub piston leads to greater high temperature area near the cylinder head, enhancing the HT in this region. On the other hand, Figure 12 at the end of the combustion cycle ( $\approx+41$ CAD aTDC) further confirms the ability of the stepped piston to propagate the high temperature until the cylinder wall. This fact, combined with the appreciable HT through the cylinder head, makes this geometry less suitable than the stock one in terms of heat transfer.

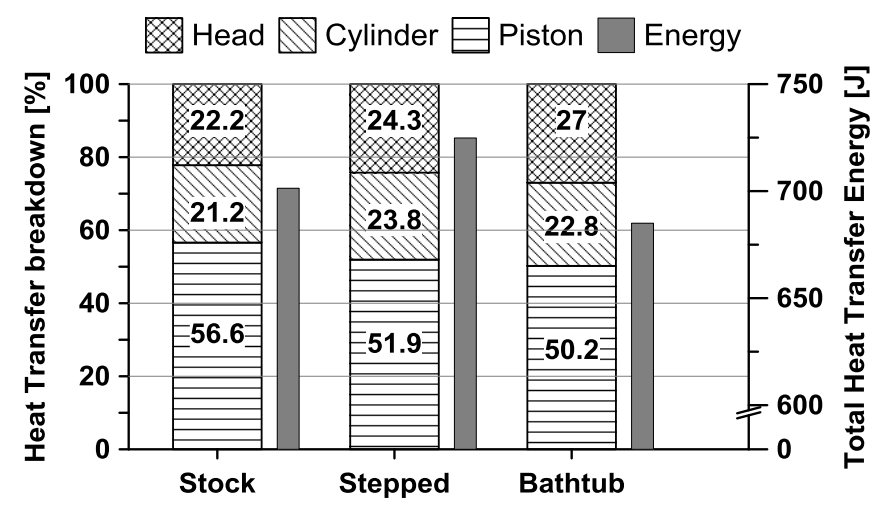

Figure 13. Comparison of the heat transfer breakdown and total heat transfer energy between the stock, stepped and bathtub pistons at medium load. 


\subsection{Combustion Losses}

From Figure 14 (left), it is highlighted that the predicted $\mathrm{HC}$ values at the end of the combustion cycle are very accurate comparing with experimental measurements. By contrast, $\mathrm{CO}$ emissions are significantly under-predicted for the three piston geometries. As found at low load conditions, the evolution of $\mathrm{HC}$ emissions as well as its variations between the different pistons are equal to those observed for the iso-octane mole fraction. However, the values at the peak of the iso-octane consumption ( $~+40$ CAD aTDC) are four orders of magnitude lower than the corresponding ones at low load, which demonstrates the improved oxidation of the iso-octane as load is increased. This fact is also confirmed by comparing the minimum $\mathrm{HC}$ values achieved at both engine loads. The improved oxidation of iso-octane at this load should be related with the higher mean temperature, which is around $100 \mathrm{~K}$ higher than at low load conditions. On the other hand, focusing on the top of Figure 14 (left and right), a clear relationship between $\mathrm{CO}$ oxidation and mean temperature can be stated. Thus, the pattern of temperature profiles for the three pistons are faithfully reproduced by the CO evolution. In this sense, colliding CO values for stepped and bathtub are observed, with higher ones for stock piston due to its lower mean temperature in the chamber.
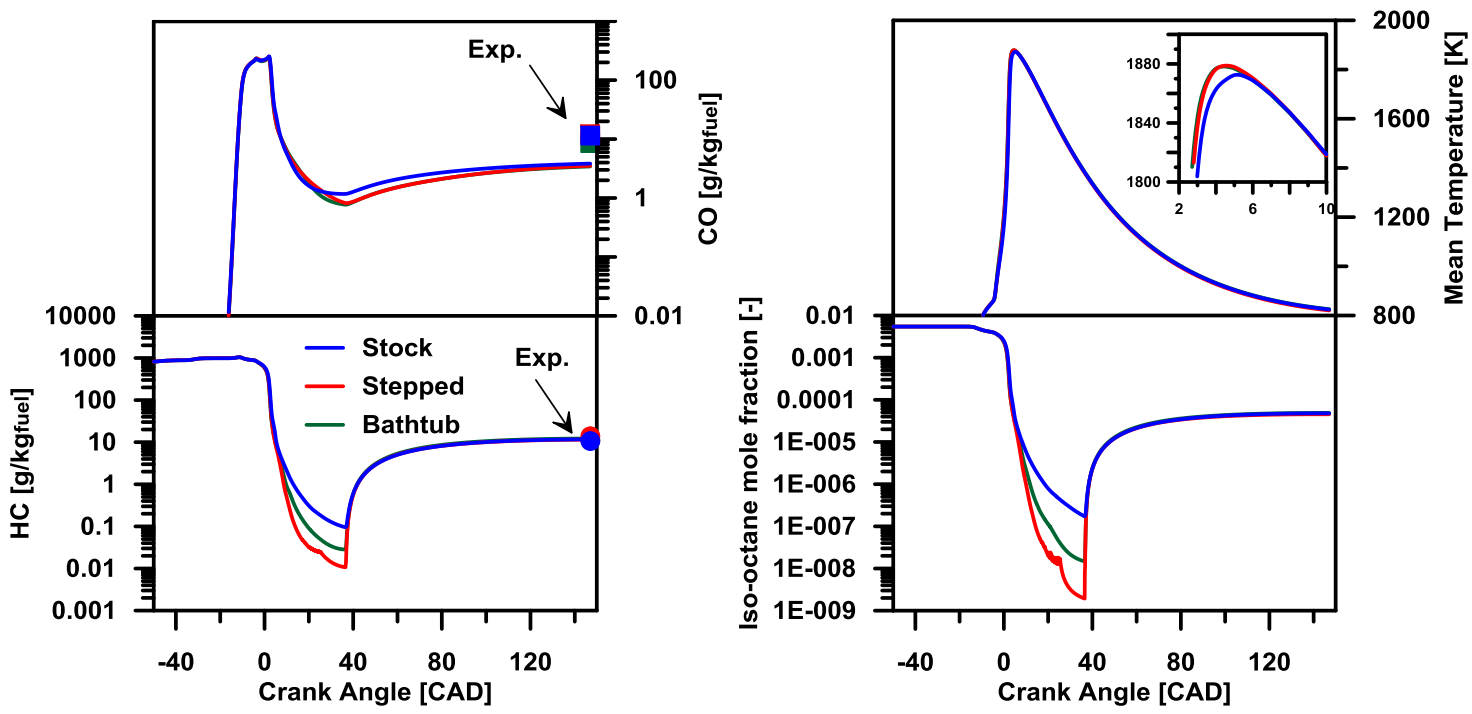

Figure 14. Comparison of the experimental and model predicted $\mathrm{HC}$ and $\mathrm{CO}$ emissions between the stock, stepped and bathtub pistons at medium load (left). Instantaneous isooctane mole fraction and mean temperature predicted by the model (right).

\subsection{Efficiency}

Figure 15 compares the fuel energy usage between the three pistons at medium load. It is stated that, as the engine load increases the gain in combustion efficiency for the bathtub piston diminishes. However, the gross indicated efficiency continues to be improved at medium load. These findings further support that reduced HT losses, from reduced piston surface area and reduced charge motion, are playing a significant role in the improvements in gross indicated efficiency for the bathtub piston over the different engine loads. On the other hand, stepped piston presents a similar apportionment of the fuel energy than the stock piston. Only a slight increase in HT losses is observed, which combined with the slightly reduced exhaust losses leads to almost equal gross indicated work. 
Comb. loss HT loss $\triangle$ Exhaust loss $⿴ 囗 ⿱ 一 一)$ G work

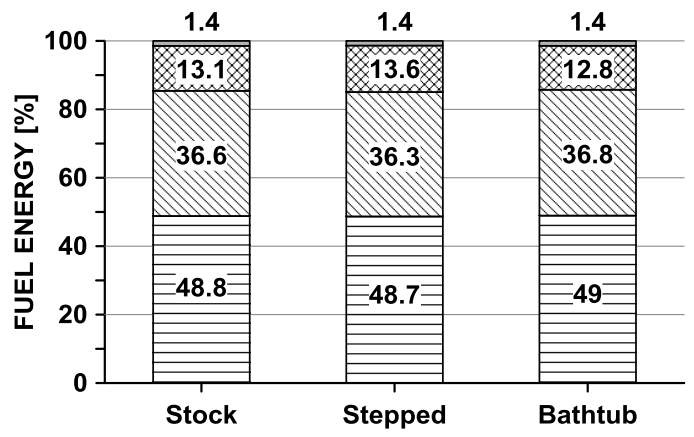

Figure 15. Comparison of the fuel energy usage between the stock, stepped and bathtub pistons at medium load.

\section{High load}

As described in [27], at this load, the engine settings were strongly modified to preserve the engine mechanical integrity. Thus, the effective compression ratio was lowered to $11: 1$, the intake temperature was set at $32^{\circ} \mathrm{C}$ and the gasoline fraction was reduced until $70 \%$. Moreover a single diesel injection was set at -6 CAD aTDC to avoid excessive pressure rise rates. The intake oxygen mass fraction was $15.8 \%$. These data is summarized in table 7.

\begin{tabular}{|l|c|}
\hline Diesel injection schedule [-] & Single \\
\hline Diesel injection timing [CAD aTDC] & -6 \\
\hline Gasoline injection timing [CAD aTDC] & -335 \\
\hline Gasoline fraction [\%] & 70 \\
\hline Total injected mass [mg] & 175 \\
\hline Intake temperature [ $\left.{ }^{\circ} \mathrm{C}\right]$ & 32 \\
\hline Engine speed [rev/min] & 1200 \\
\hline Compression Ratio [-] & $11: 1$ \\
\hline Intake oxygen mass fraction [\%] & 15.8 \\
\hline
\end{tabular}

Table 7. Operating conditions for the high load study

\subsection{Heat transfer analysis}

The global instantaneous heat flux (HF) at Figure 16, presents its minimum peak for stepped piston. The analysis of the heat fluxes at the different zones shows that this gain is combination of different factors. In particular, part of this gain is attributed to the reduction in the cylinder wall HT, overall after +20 CAD aTDC. In addition, as previously found, the highest $\mathrm{HF}$ through the piston surface is obtained for the stock geometry, with lower one observed for stepped and bathtub pistons. Finally, the cylinder head HF is notably worsened with bathtub geometry, which leads to higher global HF than stepped piston. 


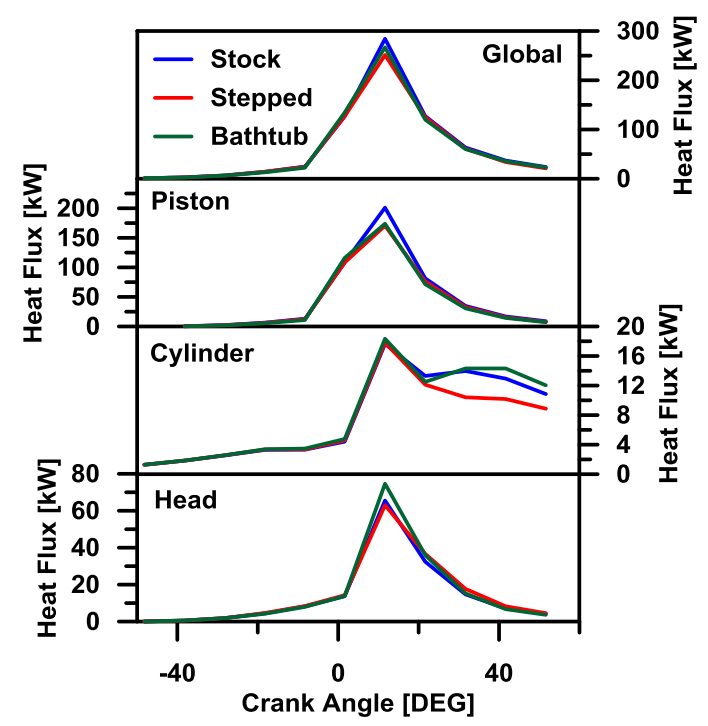

Figure 16. Heat flux breakdown between piston, cylinder and cylinder head for the stock, stepped and bathtub pistons at high load.

Figure 17 shows the differences in the in-cylinder temperature distribution between the three piston geometries. A cut plane coincident with the spray axis and an iso-surface of $T=1500 \mathrm{~K}$ are represented. Looking the figure at +1.6 CAD aTDC, it is seen that the fuel spray remains inside the piston bowl for the three geometries. The spatial start of combustion is observed in the outside of the spray plume, where reactive equivalence ratios are reached due to the oxygen availability. It is worthy to note that the end of injection event takes place at +2.2 CAD aTDC, so a certain portion of the diesel fuel is burned as a traditional mixing-controlled diesel combustion at these instants. In this sense, a colder region is appreciated near piston center due to the fuel injection. Following the cycle, at +5.5 CAD aTDC, a combustion progression from the outside of the spray plume to the centerline of the spray is confirmed. It is also observed an in-axis propagation of the high temperature to the injector nozzle. Also of note is that the fuel spray does not have enough momentum to penetrate far into the squish zone, so the high temperature gas is not capable to propagate until the crevices region. At +11.5 CAD aTDC it is seen that combustion continues to develop through the piston wall. Finally, the smoother geometry of bathtub piston allows the high temperature gas to advance until the cylinder wall in the late cycle. 


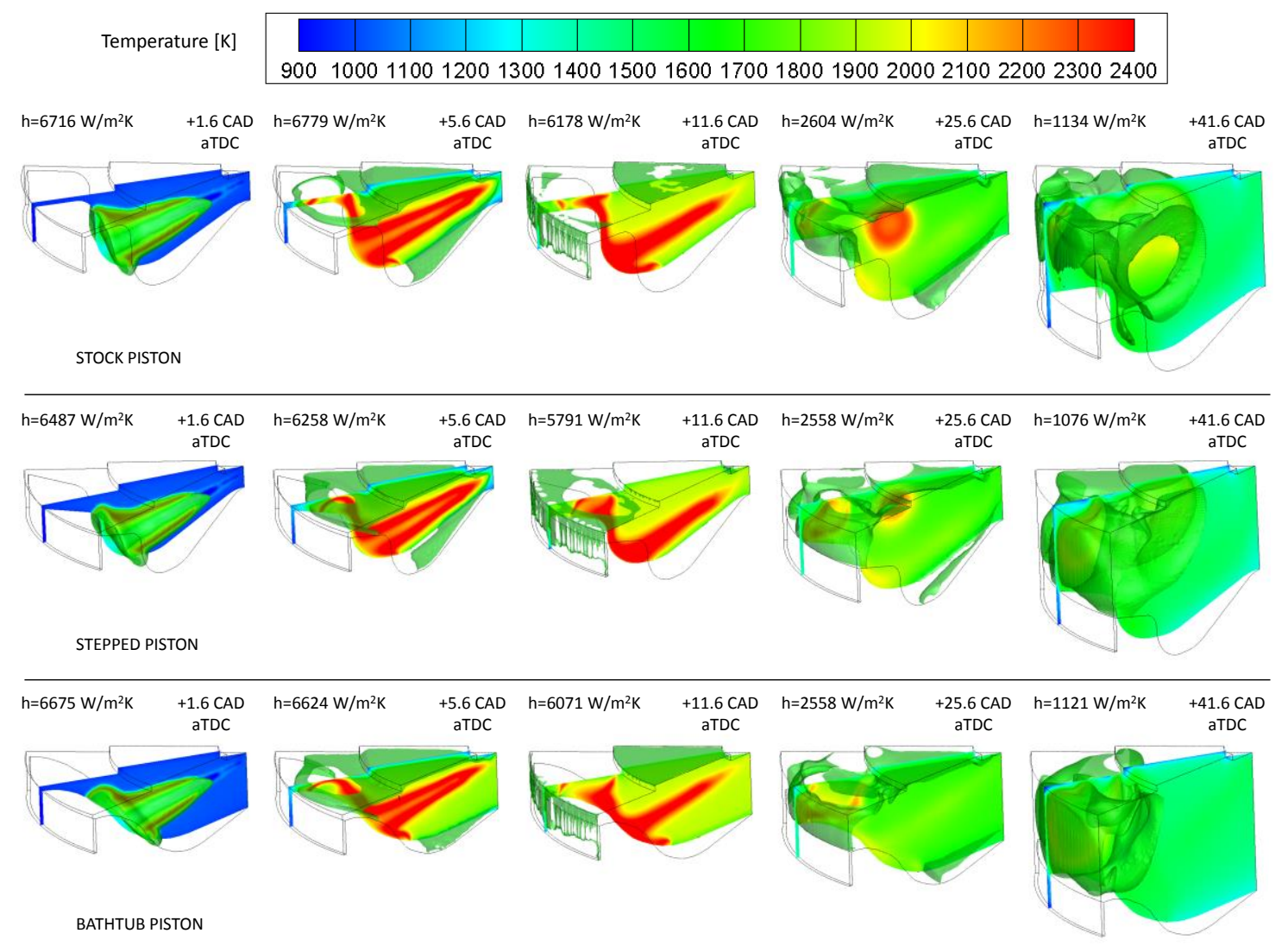

Figure 17. Comparison of the temperature distribution between the stock, stepped and bathtub pistons at high load. A cut plane coincident with the spray axis, an iso-surface of $\mathrm{T}=1500 \mathrm{~K}$ and the heat transfer coefficient are represented in each case.

As seen in Figure 18, bathtub improves the total HT energy compared with the stock piston, but stepped piston even allows greater results. Focusing on the HT breakdown is further confirmed that the reduction in piston surface area is the main cause of the improved results for bathtub piston. In addition, as seen in Figure 17 at +11.6 CAD aTDC, bathtub geometry has greater distance between the high temperature gas and the bottom part of the piston surface, which also contributes to reduce the HT there. However, it seems that the not so smooth geometry of stepped piston allows to minimize the HT through the cylinder, resulting in a better global balance. Finally, it is remarkable that the combustion behavior resulted from the single injection strategy implies around $7 \%$ higher $\mathrm{HT}$ through the piston compared to medium load conditions.

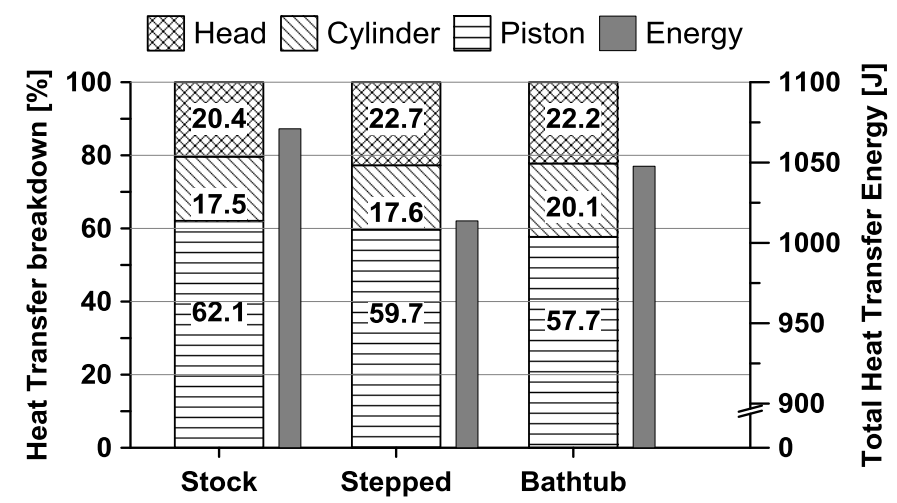

Figure 18. Comparison of the heat transfer breakdown and the total heat transfer energy between stock, stepped and bathtub pistons at high load. 


\subsection{Combustion Losses}

As seen from Figure 19, $\mathrm{HC}$ and CO levels are over-predicted by the computational calculations, overall for the two designed geometries. However, since the emissions trend between pistons is reproduced accurately, the simulations can be used to understand the differences observed in combustion efficiency. Contrary to the findings at low and medium load conditions, it is noted that the predicted $\mathrm{HC}$ emissions shape and its values at the end of the combustion cycle are not completely associated with the iso-octane mole fraction. Thus, the contribution of the diesel fuel to the total $\mathrm{HC}$ is represented in Figure 19 as the subtraction of iso-octane from total $\mathrm{HC}$ mass. The great impact of the diesel spray oxidation on the unburned products it is confirmed comparing the evolution of $\mathrm{HC}$ and this variable. In addition, $\mathrm{CO}$ emissions also show a different behavior than the one found at low and medium loads, which further confirms the influence of the diesel fuel to the final levels of combustion losses. Also of note is that the lower mean temperature predicted for bathtub piston, which promotes higher $\mathrm{HC}$ and $\mathrm{CO}$ levels.
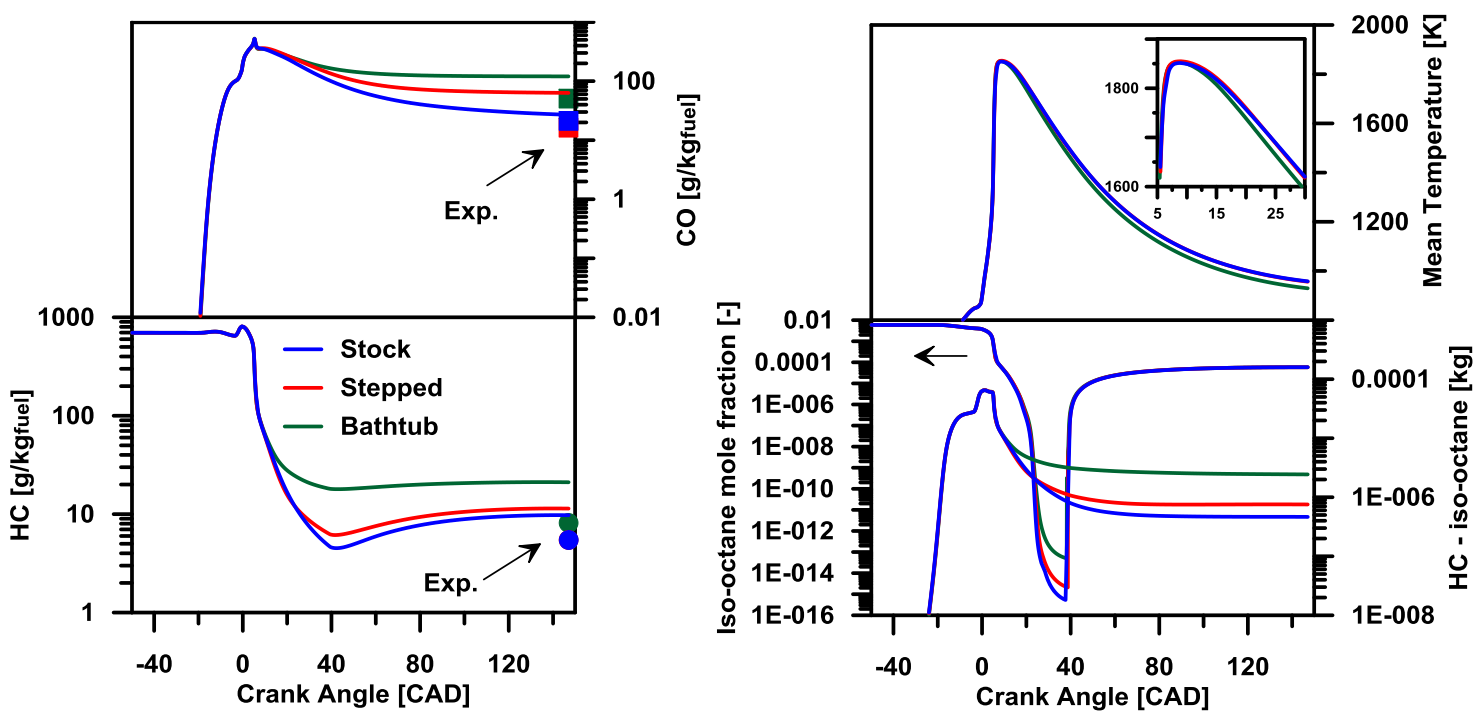

Figure 19. Comparison of the experimental and model predicted $\mathrm{HC}$ and $\mathrm{CO}$ emissions between the stock, stepped and bathtub pistons at high load (left). Instantaneous iso-octane mole fraction, mean temperature and subtraction of iso-octane from total $\mathrm{HC}$ mass predicted by the model (right).

\subsection{Efficiency}

The most remarkable finding from the fuel energy usage presented in Figure 20 is the worsening in combustion efficiency for stepped and bathtub piston compared to medium load. As demonstrated in Figure 17, the high temperature gas does not penetrate well until the crevices region, which only contains a lean mixture of air, EGR and gasoline. In this regard, the pilot diesel injection at -60 CAD aTDC used at low and medium load conditions creates more reactive equivalence ratios at this zone, which contributes to reduce the unburned products. Comparing the value of the combustion losses for three pistons to their corresponding ones at medium load, it is noted that combustion losses are worse as the squish height is increased. In this sense, squish flows seems to play an important role on that assessment. Thus, as the bowl depth is increased and the squish height is decreased, the momentum of the reverse squish flow increases, which benefits the reduction in combustion loses. Finally, it can be stated that stepped piston promotes slightly higher gross indicated work than the stock piston even with higher combustion losses. 
Comb. loss HT loss Exhaust loss $⿴$ GI work

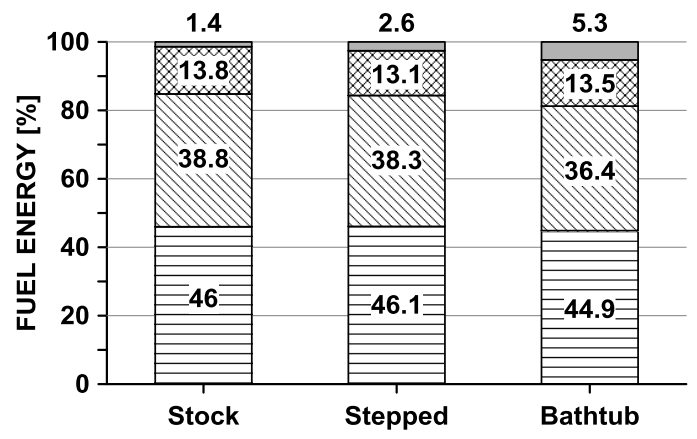

Figure 20. Comparison of the fuel energy usage between the stock, stepped and bathtub pistons at high load.

\section{Discussion}

This section is focused on the direct comparison of all the pistons with the aim of selecting the more suitable piston geometry to improve $\mathrm{RCCl}$ efficiency at the different engine loads. Thus, Figure 21 depicts the relative variation of the gross indicated work taking the stock piston as baseline. As seen from the figure, bathtub piston provides an improvement of around $1.7 \%$ at low load, a moderate improvement of $0.3 \%$ at medium load and a notable worsening of around $2.5 \%$ at high load in comparison to the stock piston. On the other hand, stepped piston not offers such a significant improvement at low load as bathtub piston, where provides an improvement of $1 \%$ versus the stock piston, but allows to maintain almost the same efficiency than the stock piston at medium and high load $(-0.2 \%$ and $+0.2 \%$ respectively). Thus, it seems that the best balanced piston for the global RCCl operation is the stepped one. It should be noted that the results presented here have not been rigorously optimized and it is expected that the combination of the engine settings may yield slightly different results.

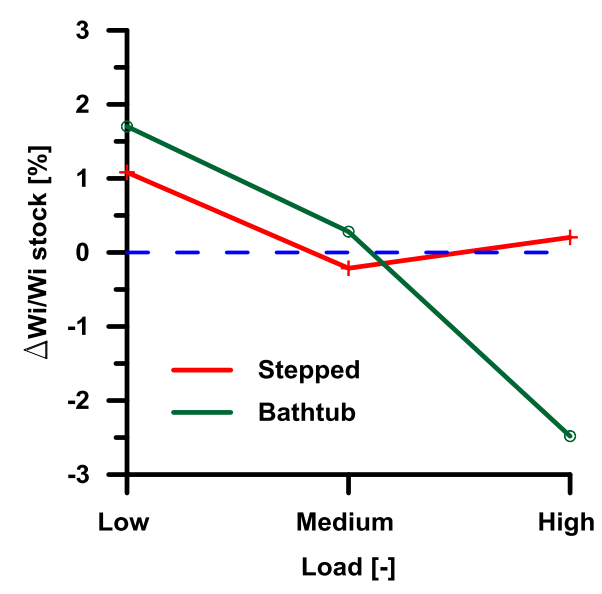

Figure 21. Overview of the designed pistons in terms of gross indicated work at low, medium and high load. Results are presented as a relative variation compared to the stock piston.

\section{Conclusions}

In the present study, the influence of the piston bowl geometry on $\mathrm{RCCl}$ heat transfer and combustion losses and its repercussion on the engine efficiency have been studied by means of computational modeling. In addition, the different engine operating conditions explored were also validated experimentally.

It has been found that the use of an advanced double injection strategy promotes the spatial start of combustion at the piston surface for the three piston geometries. Also, the use of 
delayed single injection strategy results in traditional mixing-controlled diesel combustion with the fuel spray restrained inside the piston bowl. Thus, for both injection strategies, heat flux through the piston surface represent the major portion of the heat transfer energy.

The major findings from the heat transfer analysis provide next guidelines that should be considered to optimize the piston geometry for $\mathrm{RCCl}$ combustion:

- A reduction in piston surface area through bowl shape should be looked for minimizing the global heat transfer losses. This optimization will provide additional gross work independently on the engine load.

- Assuming the same piston surface area, the bowl shallowness implies a balance that should be addressed to optimize heat transfer. Thus, an excessive smooth transition from piston bowl to crevice zone results in:

- A penalization in heat transfer losses due to increased heat flux trough the cylinder wall because combustion is not retained in the bowl.

- A benefit in global heat transfer due to an increase in squish distance which promotes lower squish velocities at TDC leading to a lower HT coefficient during the whole combustion cycle.

The notable observations from the comparison of the combustion losses between the different piston geometries at the different engine loads were as follows:

- At low and medium load, HC emissions as well as its variations between the different pistons are equal to those observed for the iso-octane mole fraction. Moreover, $\mathrm{CO}$ emissions are also related with the iso-octane ones and its evolution is directly linked with the mean temperature in the chamber. By contrast, a greater impact of the diesel spray oxidation on the unburned products has been confirmed at high load.

- At high load, the use of single injection strategy resulted in worse combustion efficiency for stepped and bathtub piston. It was demonstrated that the fuel spray does not penetrate far into the squish zone, so the high temperature gas is not capable to propagate until the crevices region to burn the lean mixture of air, EGR and gasoline. In this regard, the pilot diesel injection used at low and medium load creates more reactive equivalence ratios at this zone, which contributes to reduce the unburned products.

- Combustion losses also increased using a single diesel injection and high squish heights. It is thought to be related with the decreased momentum of the reverse squish flow, which worsens the high temperature propagation to crevices region.

Finally, the direct comparison of the gross indicated work for the different pistons showed that the best balanced piston for $\mathrm{RCCl}$ operation over the three different loads studied was the stepped one. Thus, a $1 \%$ improvement in Gl efficiency at low load with almost the same values than the stock piston at medium and high loads was observed.

\section{Acknowledgments}

The authors would like to acknowledge VOLVO Group Trucks Technology for supporting this research and to express their gratitude to CONVERGENT SCIENCE Inc. for their kind support for performing the CFD calculations using CONVERGE software. 


\section{References}

[1] Yanagihara $\mathrm{H}$, Sato $\mathrm{Y}$, Minuta J. A simultaneous reduction in NOx and soot in diesel engines under a new combustion system (Uniform Bulky Combustion System e UNIBUS). 17th International Vienna Motor Symposium, pp. 303-314, 1996.

[2]Wu H-W, Wang R-H, Ou D-J, Chen Y-C, Chen T-Y. Reduction of smoke and nitrogen oxides of a partial $\mathrm{HCCl}$ engine using premixed gasoline and ethanol with air. Applied Energy, Vol. 88, pp 3882-3890, 2011.

[3]Mingfa Y, Zhaolei Z, Haifeng L. Progress and recent trends in homogeneous charge compression ignition $(\mathrm{HCCl})$ engines. Progress in Energy and Combustion Science 35 (5) (October 2009) 398-437.

[4]Maurya R K, Agarwal A K. Experimental study of combustion and emission characteristics of ethanol fuelled port injected homogeneous charge compression ignition $(\mathrm{HCCl})$ combustion engine. Applied Energy, Vol. 88, pp 1169-1180, 2011.

[5]Lu X, Han D, Huang Z. Fuel design and management for the control of advanced compression-ignition combustion modes. Progress in Energy and Combustion Science, 37, 2011:741-783.

[6]Cerit M, Soyhan H S. Thermal analysis of a combustion chamber surrounded by deposits in an HCCl engine. Applied Thermal Engineering 50 (1) (2013) 81-88.

[7]Bessonette P W, Schleyer C H, Duffy K P, Hardy W L, Liechty M P. Effects of fuel property changes on heavy-duty HCCl combustion. SAE paper 2007-01-0191, 2007.

[8]Kalghatgi G T, Kumara Gurubaran R, Davenport A, Harrison A J, Hardalupas Y, Taylor AMKP. Some advantages and challenges of running a Euro IV, V6 diesel engine on a gasoline fuel. Fuel, Vol. 108, pp 197-207, 2013.

[9]Yu C, Wang J, Wang Z, Shuai S. Comparative study on Gasoline Homogeneous Charge Induced Ignition (HCII) by diesel and Gasoline/Diesel Blend Fuels (GDBF) combustion. Fuel, Vol. 106, pp 470-447, 2013.

[10]Kalghatgi G, Risberg P, Ångström H. Partially Pre-Mixed Auto-Ignition of Gasoline to Attain Low Smoke and Low NOx at High Load in a Compression Ignition Engine and Comparison with a Diesel Fuel. SAE Technical Paper 2007-01-0006, 2007, doi:10.4271/2007-01-0006.

[11]Kalghatgi G T. Auto-ignition quality of practical fuels and implications for fuel requirements of future SI and HCCl engines. SAE paper 2005-01-0239, 2005.

[12] Kalghatgi G, Risberg P, Angstrom H. Advantages of fuels with high resistance to autoignition in late-injection, low-temperature, compression ignition combustion. SAE Trans., 2006, 115(4), 623-634.

[13]Lewander C M, Johansson B, Tunestal P. Extending the Operating Region of Multi-Cylinder Partially Premixed Combustion using High Octane Number Fuel. SAE Paper 2011-01-1394; 2011.

[14] Liu H, Yao M, Zhang B, Zheng Z. Effects of inlet pressure and octane numbers on combustion and emissions of a homogeneous charge compression ignition $(\mathrm{HCCl})$ engine. Energy and Fuels, 2008, 22(4), 2207-2215.

[15]Christensen M, Hultqvist A, Johansson B. Demonstrating the multi-fuel capability of a homogeneous charge compression ignition engine with variable compression ratio. SAE paper 1999-01-3679, 1999. 
[16]Benajes J, García A, Domenech V, Durrett R. An investigation of partially premixed compression ignition combustion using gasoline and spark assistance. Applied Thermal Engineering, Volume 52, Issue 2, 15 April 2013, Pages 468-477.

[17]Pastor JV, García-Oliver JM, García A, Micó C, Durrett R. A spectroscopy study of gasoline partially 365 premixed compression ignition spark assisted combustion. Applied Energy 2013;104:568-75. 366.

[18]Benajes J, García A, Tormos B, Monsalve-Serrano J. Impact of Spark Assistance and Multiple Injections on Gasoline PPC Light Load. SAE Int. J. Engines 7(4):2014, doi:10.4271/2014-01-2669.

[19]Desantes JM, Payri R, García A, Monsalve Serrano J. Evaluation of Emissions and Performances from Partially Premixed Compression Ignition Combustion using Gasoline and Spark Assistance. SAE Technical Paper 2013-01-1664, 2013, doi:10.4271/2013-01-1664.

[20]Benajes J, Molina S, García A, Monsalve-Serrano J, Durrett R. Conceptual model description of the double injection strategy applied to the gasoline partially premixed compression ignition combustion concept with spark assistance. Applied Energy, Volume 129, 15 September 2014, Pages 1-9.

[21]Benajes J, Molina S, García A, Monsalve-Serrano J, Durrett R. Performance and engine-out emissions evaluation of the double injection strategy applied to the gasoline partially premixed compression ignition spark assisted combustion concept. Applied Energy, Volume 134, 1 December 2014, Pages 90-101.

[22]Splitter D A, Wissink M L, Hendricks T L, Ghandhi J B, Reitz R D. Comparison of RCCI, HCCl, and CDC Operation from Low to Full Load, THIESEL 2012 Conference on Thermo- and Fluid Dynamic Processes in Direct Injection Engines, 2012.

[23]Kokjohn S L, Hanson R M, Splitter D A, Reitz R D. Fuel reactivity controlled compression ignition (RCCI): a pathway to controlled high-efficiency clean combustion, International Journal of Engine Research, 2011. Volume 12, June 2011, Pages 209-226.

[24]Benajes J, Pastor JV, García A, Monsalve-Serrano J. The potential of RCCl concept to meet EURO VI NOx limitation and ultra-low soot emissions in a heavy-duty engine over the whole engine map. Fuel, Volume 159, 1 November 2015, Pages 952-961.

[25]Benajes J, Molina S, García A, Monsalve-Serrano J. Effects of low reactivity fuel characteristics and blending ratio on low load $\mathrm{RCCl}$ (reactivity controlled compression ignition) performance and emissions in a heavy-duty diesel engine. Energy, Volume 90, October 2015, Pages 1261-1271.

[26]Benajes J, Molina S, García A, Monsalve-Serrano J. Effects of Direct injection timing and Blending Ratio on $\mathrm{RCCl}$ combustion with different Low Reactivity Fuels. Energy Conversion and Management, Volume 99, 15 July 2015, Pages 193-209.

[27] Molina S, García A, Pastor JM, Belarte E, Balloul I. Operating range extension of RCCI combustion concept from low to full load in a heavy-duty engine. Applied Energy, Volume 143, 1 April 2015, Pages 211-227.

[28]Desantes JM, Benajes J, García A, Monsalve-Serrano J. The Role of the In-Cylinder Gas Temperature and Oxygen Concentration over Low Load RCCI Combustion Efficiency. Energy, Volume 78, 15 December 2014, Pages 854-868. 
[29]Splitter D A, Kokjohn S L, Wissink M L, Reitz R. Effect of compression ratio and piston geometry on RCCI load limits and efficiency. SAE technical paper 2012-01-0383; 2012.

http://dx.doi.org/10.4271/2012-01-0383.

[30]Kono M, Basaki M, Ito M, Hashizume T, Ishiyama S, Inagaki K. Cooling Loss Reduction of Highly Dispersed Spray Combustion with Restricted In-Cylinder Swirl and Squish Flow in Diesel Engine. SAE Int. J. Engines 5(2):2012.

[31]Payri F, Olmeda P, Martín J, García A. A complete OD thermodynamic predictive model for direct injection diesel engines. Applied Energy, Volume 88, Issue 12, December 2011, Pages 4632-4641.

[32]Senecal P K, Richards K J, Pomraning E, Yang T, Dai M Z, McDavid R M, Patterson M A, Hou S, Shethaji T. A New Parallel Cut-Cell Cartesian CFD Code for Rapid Grid Generation Applied to In-Cylinder Diesel Engine Simulations. SAE 2007-01-0159, 2007, doi:10.4271/2007-01-0159.

[33]Dukowicz J. A particle fluid numerical model for liquid sprays. J. Comput. Phys., vol. 2, pp. 111-566, 1980.

[34]Han Z, Reitz R D. A Temperature Wall Function Formulation for Variable Density Turbulence Flow with Application to Engine Convective Heat Transfer Modeling. Int. J. Heat and Mass Transfer, Vol. 40, 1997.

[35]Babajimopoulos A, Assanis D N, Flowers D L, Aceves S M, Hessel R P. A fully coupled computational fluid dynamics and multi-zone model with detailed chemical kinetics for the simulation of premixed charge compression ignition engines. International Journal of Engine Research, Vol. 6, 2005.

[36]Ra Y, Reitz R D. A reduced chemical kinetic model for IC engine combustion simulations with primary reference fuels. Combust. Flame, 2008, 155(4), 713-738.

[37]Ra Y, Reitz R D. The application of a multicomponent droplet vaporization model to gasoline direct injection engines. Int. J. Engine Res., 2003, 4(3), 193-218.

[38]Kokjohn S, Hanson R, Splitter D, Kaddatz J, et al. Fuel Reactivity Controlled Compression Ignition (RCCI) Combustion in Light- and Heavy-Duty Engines. SAE Int. J.Engines 4(1):360-374, 2011, doi:10.4271/2011-01-0357.

[39] Namazian M, Heywood J B. Flow in the Piston-Cylinder-Ring Crevices of a Spark-Ignition Engine: Effect on Hydrocarbon Emissions, Efficiency and Power. SAE Technical Paper 820088, 1982.

\section{Abbreviations}

aTDC: After Top Dead Center

CAD: Crank Angle Degree

CDC: Conventional Diesel Combustion

CO: Carbon Monoxide

$\mathrm{Cl}$ : Compression Ignition

DI: Direct Injection

DPF: Diesel Particulate Filter

EGR: Exhaust Gas Recirculation 
EVC: Exhaust Valve Close

EVO: Exhaust Valve Open

FSN: Filter Smoke Number

HC: Hydro Carbons

$\mathrm{HCCl}$ : Homogeneous Charge Compression Ignition

HD: Heavy Duty

HF: Heat flux

HT: Heat transfer

ICE: Internal Combustion Engine

IVC: Intake Valve Close

IVO: Intake Valve Open

LNT: Lean NOx Trap

LTC: Low Temperature Combustion

ON: Octane Number

PM: Particulate Matter

PFI: Port Fuel Injection

PPC: Partially Premixed Charge

PRF: Primary reference fuel

RCCI: Reactivity Controlled Compression Ignition

RoHR: Rate of Heat Release

SCR: Selective Catalytic Reduction 